http://jmscr.igmpublication.org/home/ ISSN (e)-2347-176x ISSN (p) 2455-0450

crossref DOI: https://dx.doi.org/10.18535/jmscr/v8i11.28

Journal Of Medical Science And Clinical Research

\title{
Aneurysmal Bone Cyst Of Proximal Ulna - An Unusual Presentation A Case Report
}

\author{
Authors \\ Dr V.Manoj ${ }^{1}$, Dr P. Ramya Krishna ${ }^{2}$, Dr. P.Sivananda ${ }^{3}$ \\ ${ }^{1,2}$ Junior Resident of Orthopaedics, Andhra Medical College, Visakhapatnam, India \\ ${ }^{3}$ Professor of Orthopaedics, Andhra Medical College, Visakhapatnam, India
}

\begin{abstract}
Introduction: An aneurysmal bone cyst is a rare,benign, destructive,hemorrhagic and,expansile lesion accounting for $1 \%$ of all bone tumorswith a thin wall containing blood-filled cystic cavities. The termAneurysmal is derived from the macroscopic appearance of a sponge-liketumor containing numerous giant cells. This type of lesionpredominantly affects the metaphysis of the long bone.

Case Report: we present a case of a 14-year-old female patient presented with an aneurysmal bone cyst of the right proximal ulna. It is an unusual presentation for its location, which presented with swelling and pain progressive over three months. The plain radiograph showed an expansile lytic lesion with a thin shell of cortical bone at the proximal ulna. Surgical exploration shows a pulsatile blood-filled cystic lesion.

Results: Postoperatively uneventful.The patient was prescribed physiotherapy and was advised for monthly follow-up. The patient had a full range of motion at the last follow up visit and was conveniently able to do his daily activities.

Conclusion: An aneurysmal bone cyst is a destructive, hemorrhagic, and tumor-like lesion occurring predominantly in teenaged patients. Radiographs and MRI scans can often confirm ABC's diagnosis; Excision of tumor and replacement of bone defects with anautograft are considered safe procedures with minimal recurrence risk.

The present study describes a sporadic case of an ABC in the proximal ulna. It highlighted the importance of radiological and MRI for the diagnosis of the aneurysmal bone cyst.
\end{abstract}

\section{Introduction}

Aneurysmal bone cysts are locally destructive, blood-filledreactive lesions of bone and are not considered trueneoplasms. Any type ofbone may be involved, but the most commonlocations include the proximal humerus, distal femur, proximaltibia, and spine.it is most commonly seen in patients younger than 20 years old, and there is a slightly female predominance. This case report shows an unusual presentation of aneurismal bone cyst in proximal ulna.

\section{Case Report}

We present a case of a 14-year-old female patient with an aneurysmal bone cyst of the proximal ulna. It is an unusual presentation for its location. The patient complains of swelling in the right elbow joint, which was gradually increasing over the past three months. The patient complains of tenderness over the swelling. 


\section{JMSCR Vol||08||Issue||11||Page 159-163||November}

\section{Investigations}

X-ray right elbow joint shows an expansile lytic lesion covered with a thin shell of cortical bone.
The blood investigation and ultra-sounded guided biopsy, and MRI, were done.

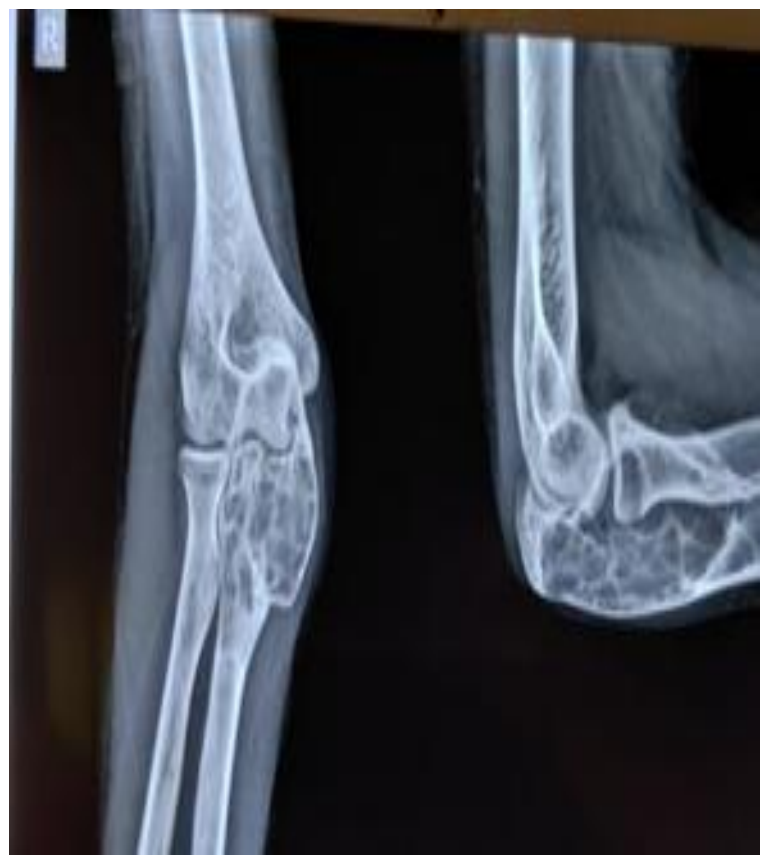

Figure-1 X-rays showed an expansile lytic lesion covered with a thin shell of cortical bone.

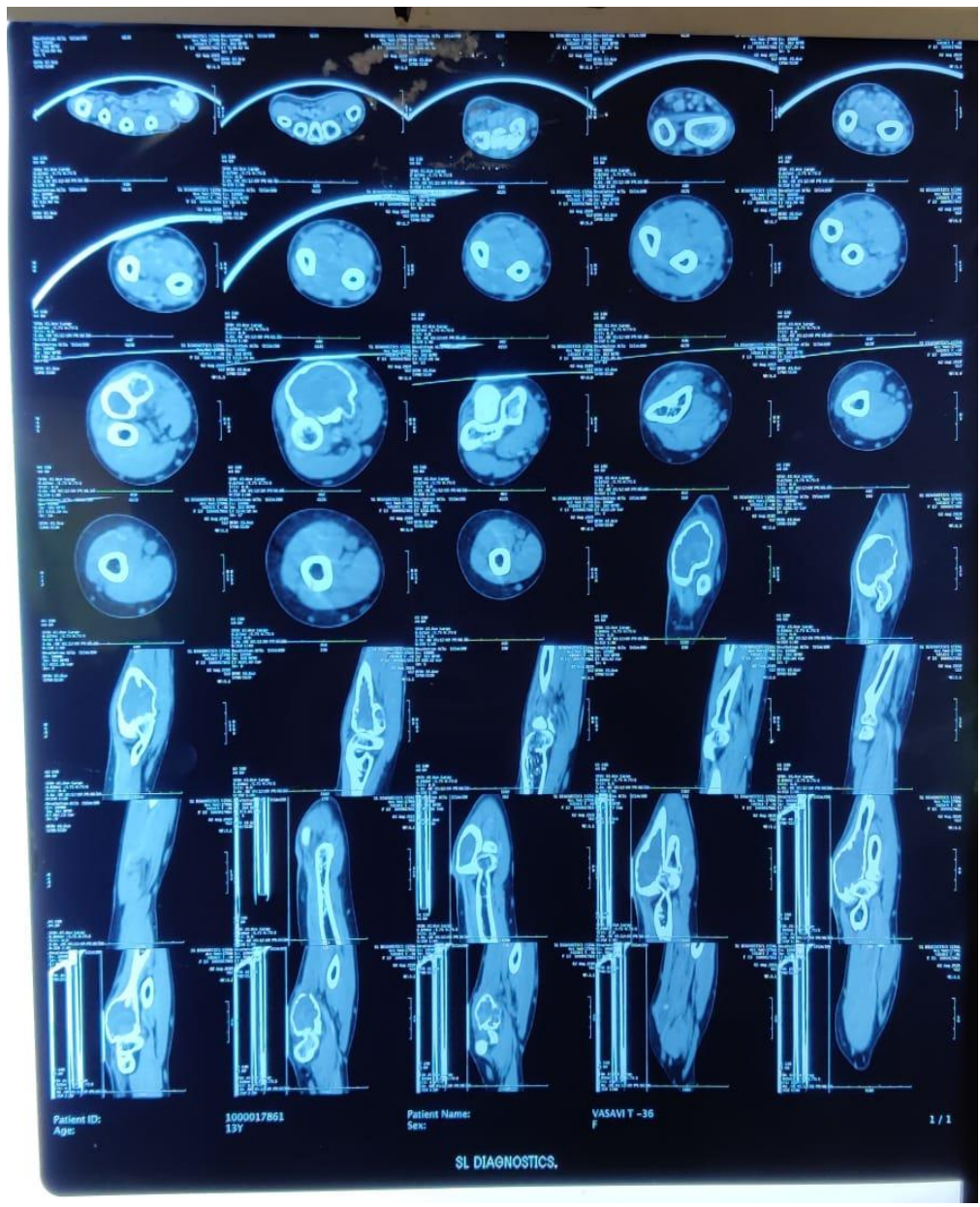

Figure-2 MRI Showing Intra Lesional Septations 


\section{JMSCR Vol||08||Issue||11||Page 159-163||November}

\section{Treatment}

The posterior approach addressed the lesion,extended curettage was done, and fibular stud graftwas taken fromthe right side and placed over the deficit area.

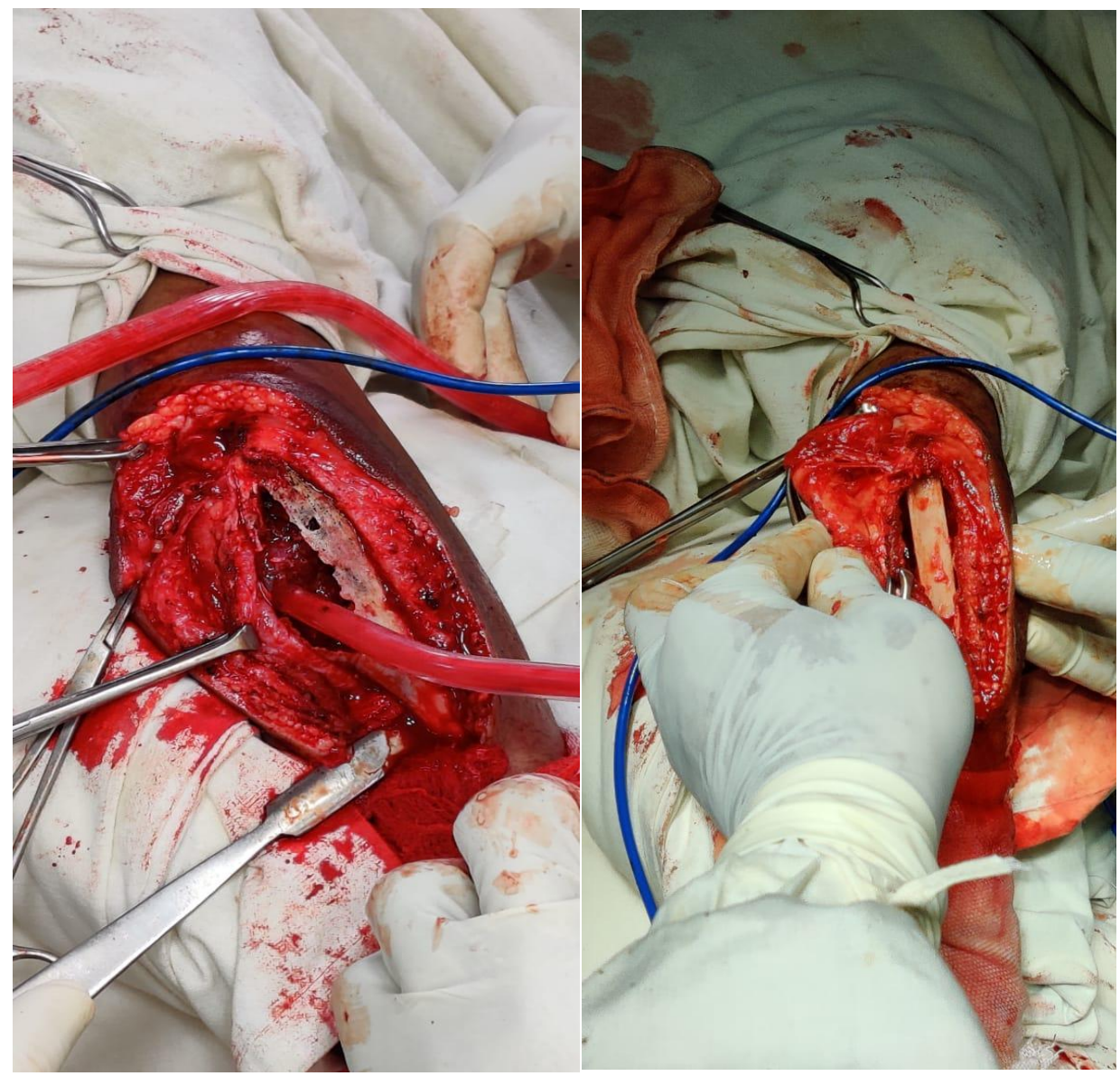

Figure-3 Intra Op Picture

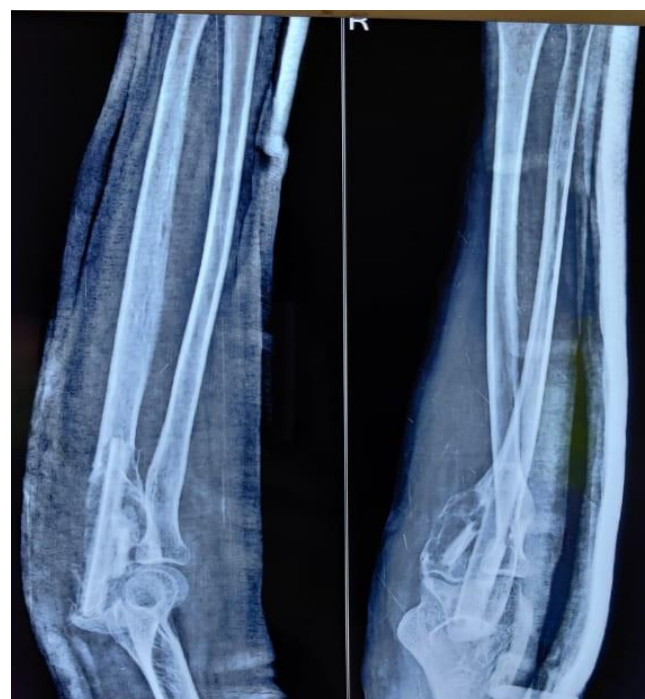

Figure-4 Immediate Post op Xray

The elbow was immobilized for six weeks, followed by a continuous passive and active range of movements done.The final follow up at the end of 6 months was entirely satisfied with an almost full ROM. 

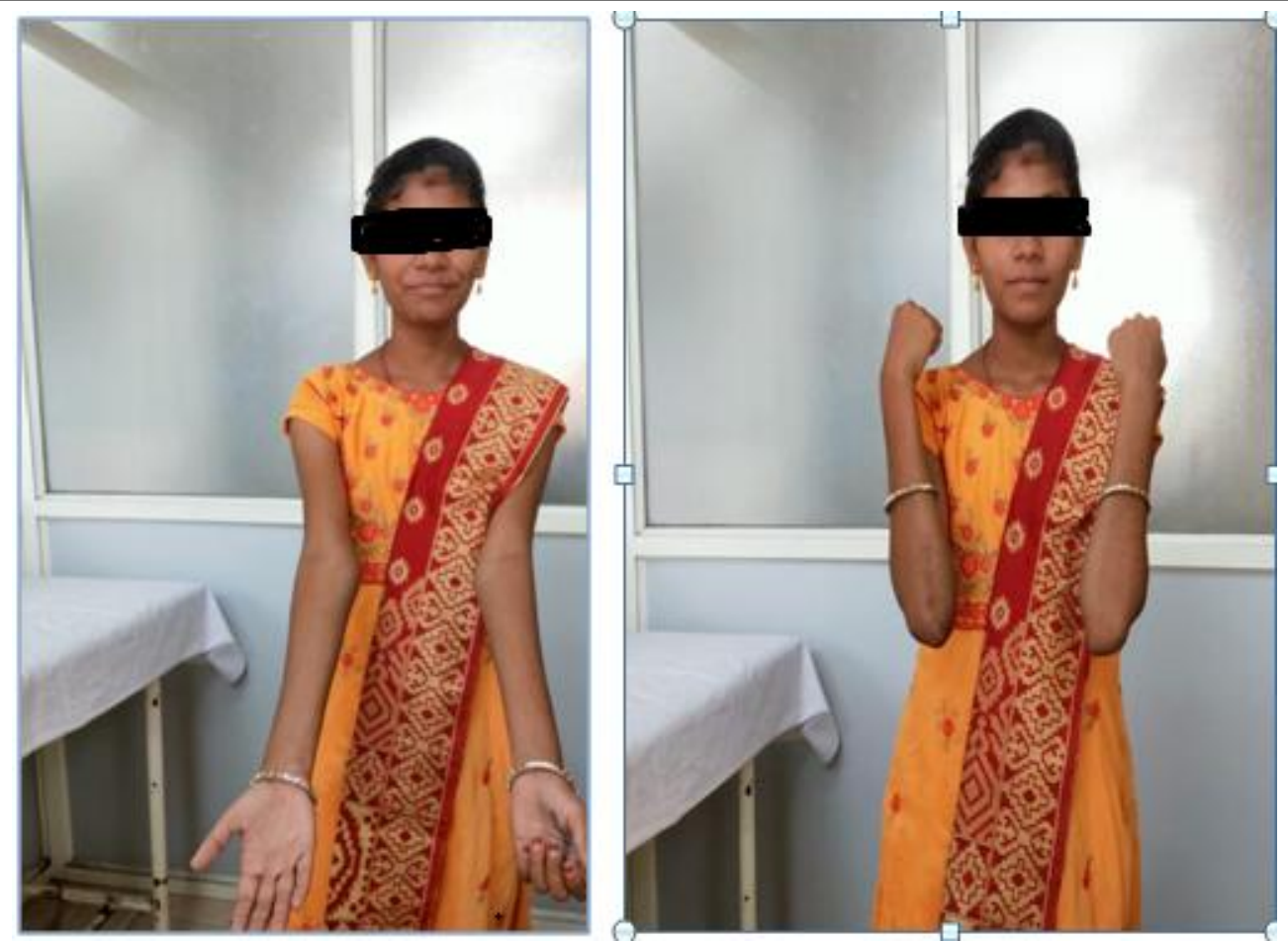

Figure-5 Elbow Rom at Six Months Follow up

\section{Discussion}

An aneurysmal bone cyst is a benign aggressive tumor of bone notorious for its recurrence after resection. Aneurysmal bone cysts account for $1 \%$ of all primary bone lesions sampled for biopsy ${ }^{[1]}$. The pathogenesis of $\mathrm{ABC}$ involves increased venous pressure locally inside the metaphyseal area of the involved bone with the development of dilated and enlarged vascular spaces within the affected bone ${ }^{[2]}$. ABC's differential diagnosis includes other giant cell tumor variants viz Brown tumor, Giant cell reparative granuloma, and Osteoclastoma. GCT comprises multinucleated giant cells and is locally aggressive and occurs eccentrically in the epiphysis ${ }^{[3,4,5]}$. But $A B C$ is a metaphyseal lesion. Surgical excision and bone grafting is the treatment of choice. The lesion is approached through anatomical approach and opened with a wide window and excised with curettage. Filling the remaining void with cancellous bone graft is the preferred treatment ${ }^{[6]}$. The present case posed a unique problem of lack of sufficient harvestable cancellous bone stock akin to her age. Hence we opted for a cortical bone graft from the ipsilateral fibula. She was 14 years old. Her riser grade was 4 .We treated the curetted area of the endosteal surface with carbolic acid to prevent a recurrence. We did not use any implant to fix the graft into the dead space. We chose the size of the graft to be slightly more than the resected bone length. Sagar Patel et al. published a case report in 2017 from Dhiraj General Hospital Piparia. They also used ipsilateral fibular graft for $\mathrm{ABC}$ of proximal ulna without treating the endosteal surface and fixing the graft with a $\mathrm{k}$ wire for 16 weeks. Their patient was a male aged 16 years. They reported nonrecurrence over six months and achieved a complete range of elbow joints ${ }^{[7]}$.

\section{Conclusion}

It is sporadic for the aneurysmal bone cyst to occur at the proximal ulna

Radiographs and MRI scans are required to confirm the diagnosis of $\mathrm{ABC}$.

\section{References}

1. Freiberg A, Loder R, Heidelberger K, and Hensinger RN: Aneurysmal bone cysts in young children. D J Pediatr Orthop 14: 8691, 1994. 
2. Cottalorda $\mathrm{J}$ and Bourelle S: Modern concepts of a primary aneurismal bone cyst. Arch Orthop Trauma Surg 127:105114, 2007.

3. Foo LF and Raby N: Tumours and tumorlike lesions in the foot and ankle. Clin Radiol 60: 308-3332, 2005.

4. Ratner V and Dorfman HD: Giant-cell reparative granuloma of the hand and foot bones. Clin Orthop Relat Res 260: 251258, 1990.

5. Futamura N, Urakawa $\mathrm{H}$, Tsukushi S, Arai E, Kozawa E, Ishiguro N, and Nishida Y: Giant cell tumor of bone arising in long bones possibly originates from the metaphyseal region. Oncol Lett 11: 26292634, 2016.

6. Boubbou M, Atarraf K, Chater L, Afifi A, and Tizniti S: Aneurysmal bone cyst primary-about eight pediatric cases: Radiological aspects and review of the literature. Pan Afr Med J 15: 111, 2013.

7. Dr. Sagar Patel, Dr. Parth Thakor, Dr. Jainish Patel, Dr. Dhruven Kosada, and Dr. Sarvang Desai.A rare case of proximal ulna aneurysmal bone cyst treated with fibular stud graft. International Journal of Advanced Research 5(11):2320-5407. 